\title{
Época de aplicação e desempenho de fungicidas no controle da giberela em trigo
}

\author{
Time of application and fungicide performance in the control of wheat scab
}

\author{
Ricardo Trezzi Casa $^{{ }^{*}}$ Amauri Bogo ${ }^{\mathrm{I}}$ Éder Novaes Moreira ${ }^{\mathrm{II}}$ \\ Paulo Roberto Kuhnem Junior ${ }^{I I}$
}

\section{RESUMO}

O controle químico da giberela pode ser influenciado pelo momento da aplicação e pelo fungicida. $\mathrm{Na}$ safra agrícola de 2004, os fungicidas foram aplicados em três estádios de crescimento da planta: início da floração, metade da floração completa e no início do desenvolvimento de grão leitoso. Em 2005, uma única aplicação foi feita no início da floração, testando-se maior número de fungicidas. As aplicações foram feitas com pulverizador manual, com pressão gerada por gás $\mathrm{CO}_{2}$, numa vazão de 200L ha-1. A intensidade da giberela foi quantificada pela incidência, severidade e índice de giberela. Também foram determinados o rendimento de grãos, o peso de mil grãos e a incidência de Fusarium graminearum nos grãos colhidos. O maior percentual de controle da giberela ocorreu com aplicação feita no início da floração. Os fungicidas metconazole $(0,09 \mathrm{~L}$ i.a. $\left.\mathrm{ha}^{-1}\right)$, tebuconazole $(0,15)$, trifloxistrobina+tebuconazole (0,075+0,15), azoxistrobina+ciproconazole $(0,060+0,024) e$ piraclostrobina+epoxiconazole $(0,099+0,037)$ reduziram significativamente a intensidade da giberela, obtendo-se controle médio de $46 \%$ na incidência, 46,6\% na severidade e $71,2 \%$ no índice de giberela. Esses fungicidas mostraram ganho médio no rendimento de grãos de $23,4 \%$, porém apresentaram baixa eficácia no controle da infecção de $\boldsymbol{F}$. graminearum nos grãos.

Palavras-chave: controle químico, Gibberella zeae, Triticum aestivum.

\section{ABSTRACT}

The chemical control of the wheat scab can be affected by time of application and fungicide. In the 2004 growing season, the fungicides were applied in the plant growth stage of beginning of flowering, half of complete flowering and beginning of soft dough stage. In the 2005 growing season, one only fungicides application was done in the beginning of the flowering with a larger number of fungicides. The applications were done with manual spray, with $\mathrm{CO}$ gas pressure in an outflow of $200 \mathrm{~L} \mathrm{ha}^{-1}$. The intensity of wheat scab was quantified by the incidence, severity and index of giberela. Grain yield, weight of a thousand grains and the incidence of Fusarium graminearum in the grains were also evaluated. The high porcentual of wheat scab control occurred when the application was done in the beginning of the flowering. The fungicides metconazol $(0.09 \mathrm{~L}$ i.a. $\left.\mathrm{ha}^{-1}\right)$, tebuconazol (0.15), trifloxystrobin+tebuconazol $(0.075+0.15)$, azoxystrobin+ciproconazol $(0.060+0.024)$ and pyraclostrobin +epoxiconazol $(0.099+0.037)$ reduced significantly the intensity of giberela wheat, obtaining average control of $46 \%$ on incidence, $46.6 \%$ on severity and $71.2 \%$ on index of giberela wheat. These fungicides showed grain yield average of $23.4 \%$, but a low efficiency on F. graminearum infection control in grains.

Key words: chemical control, Gibberella zeae, Triticum aestivum.

\section{INTRODUÇÃO}

A giberela em cereais de inverno pode ter como agentes causais várias espécies de Fusarium. Na Região Sul do Brasil, o fungo Gibberella zeae (Schw.) Petch. (anamorfo Fusarium graminearum Schwabe) é o agente causal predominante na giberela do trigo (REIS \& CASA, 2005). A doença é de ocorrência generalizada no mundo, causando danos significativos na produção de trigo em regiões onde coincidem clima úmido e quente durante a fase de floração (SUTTON, 1982; PARRY et al., 1995; REIS et al., 1996b; McMULLEN et al., 1997).

\footnotetext{
'Departamento de Fitotecnia, Centro de Ciências Agroveterinárias (CAV), Universidade do Estado de Santa Catarina (UDESC), Lages, SC, Brasil. E-mail: a2rtc@cav.udesc.br e a2ab@cav.udesc.br. *Autor para correspondência.

${ }^{\text {IIC }}$ urso de Agronomia, CAV/UDESC, Lages, SC, Brasil.
} 
Hoje a giberela é considerada a doença do plantio direto. A sobrevivência saprofítica do patógeno em diversos hospedeiros, como espécies de plantas cultivadas, nativas e invasoras (REIS \& CASA, 2004), assim como a facilidade de dispersão dos ascosporos, transportados a longa distância pelo vento, faz com que a giberela não seja controlada eficientemente pela rotação de culturas (ZAMBOLIM et al., 2000; REIS \& CASA, 2005). A grande disponibilidade de inóculo no ar (PANISSONN et al., 2002b; DEL PONTE et al., 2005), durante o período de floração (antese), associada a períodos de molhamento contínuo (REIS \& BLUM, 2004), ocorrentes com freqüência na Região Sul do Brasil, tem levado a danos significativos na cultura no trigo (PANISSON et al., 2003; CASA et al., 2004 a,b).

O escalonamento da época de semeadura e o uso de cultivares com diferentes ciclos são estratégias de escape que possibilitam que as plantas possam atingir o período de predisposição sob condições climáticas adversas ou menos favoráveis ao patógeno (REIS \& CASA, 2005). No Brasil, ainda não estão disponíveis pela pesquisa cultivares resistentes à doença. Há indicação de cultivares com diferentes níveis de tolerância (LIMA et al., 2000; INDICAÇÕES, 2005). A aplicação de fungicidas específicos na floração é uma estratégia recomendada. A eficácia de controle depende principalmente do fungicida e do momento de aplicação (REIS et al., 1996a; PANISSON et al., 2002a). Mesmo assim, o controle químico não tem apresentado eficiência satisfatória. Um dos problemas é a dificuldade de o fungicida atingir o alvo biológico, que são as anteras do trigo, seja pelo longo período de florescimento ou pela deposição do fungicida. Em anos com excesso de chuva, duas aplicações podem ser necessárias para reduzir a infecção. Além disso, a colonização subseqüente do tecido após a infecção não tem sido eficientemente paralisada a nível de campo após a aplicação do fungicida. Neste trabalho, procurou-se identificar fungicidas e período de aplicação capazes de evitar o processo de infecção e/ ou paralisar a colonização de $\boldsymbol{G}$ z zeae em espigas de trigo.

\section{MATERIAL E MÉTODOS}

Na safra agrícola de 2004, o experimento foi conduzido em lavoura comercial na NBN Sementes, no município de Muitos Capões, RS. A lavoura se localiza na região fisiográfica dos Campos de Cima da Serra, com altitude de aproximadamente $940 \mathrm{~m}$ e com solo do tipo latossolo vermelho escuro distrófico.

A semeadura do trigo "BRS Louro" foi feita no dia 13 de julho, em área de plantio direto e rotação de culturas, utilizando semeadora Semeato SHM, com espaçamento entre linhas de $18 \mathrm{~cm}$ e mantendo uma densidade populacional próxima de 450 sementes $\mathrm{m}^{-2}$.
A adubação de base constou de $440 \mathrm{~kg} \mathrm{ha}^{-1}$ da fórmula 10-25-27 (NPK). O nitrogênio em cobertura foi aplicado no dia 20 de agosto (38 dias após a semeadura), na dose de $204 \mathrm{~kg} \mathrm{ha}^{-1}$ de uréia (45\% de N). O controle de plantas daninhas foi feito somente no momento da dessecação, usando-se o herbicida glifosato (Roundup WG). O controle de insetos foi feito somente para lagartas, usando-se o inseticida triflumurom (Certero 480 SC). O controle de doenças foliares foi feito pela aplicação do fungicida tebuconazole (Folicur 200 CE), combasenolimiardedanoeconômico(INDICAÇÕES, 2005).

As unidades experimentais constaram de parcelas com nove linhas de semeadura e cinco metros de comprimento. Utilizou-se o delineamento experimental de blocos ao acaso com quatro repetições.

Os fungicidas para controle da giberela foram aplicados no início da antese (EC 60 da escala de ZADOKS et al., 1974), na metade da antese completa (EC 64) e no desenvolvimento de grão leitoso (EC 70), respectivamente nos dias 6, 13 e 20 de outubro de 2004. As pulverizações foram realizadas com pulverizador manual de precisão, com pressão constante gerada por gás CO , equipado com bicos leques XR 11002, com volume ${ }^{2}$ de calda de $200 \mathrm{~L} \mathrm{ha}^{-1}$. Os fungicidas testados foram: tebuconazole (Folicur $200 \mathrm{CE}=0,15 \mathrm{~L}$ de i.a. ha ${ }^{-1}$ ), trifloxistrobina+tebuconazole (Nativo 100+200 SC = 0,060+0,12 e 0,075+0,15L de i.a.) e metconazole (Caramba $90 \mathrm{CE}=0,081 \mathrm{~L}$ de i.a.).

Foram avaliadas as seguintes variáveis: intensidade da giberela, rendimento de grãos, peso de mil grãos e incidência de $\boldsymbol{F}$. graminearum nos grãos colhidos. A intensidade da giberela foi quantificada pela incidência, severidade e índice de giberela, em 25 espigas, coletadas, ao acaso, nas três linhas centrais de cada parcela, no estádio de maturação (EC 89). Nesta época, as espigas foram cortadas e levadas para o Laboratório de Fitopatologia do Centro de Ciências Agroveterinárias-CAV/UDESC. Considerou-se espiga doente (giberelada) aquela com a presença de, no mínimo, uma espigueta infectada, apresentando sintomas característicos da doença. A severidade foi determinada contando-se o número de espiguetas infectadas por espiga. Os dados de severidade foram expressos em porcentagem, obtidos do número médio de espiguetas gibereladas em função do número médio de espiguetas por espiga. $O$ índice de giberela foi calculado pela seguinte equação: IG= (I x S)/100, em que I é incidência e $S$ é severidade. $O$ rendimento de grãos foi determinado colhendo-se manualmente as espigas das três linhas centrais da parcela. As espigas foram trilhadas com posterior limpeza e pesagem dos grãos com ajuste do teor de umidade. O peso de mil grãos foi determinado separando-se manualmente os grãos, com posterior pesagem em balança eletrônica de precisão. A incidência de $\boldsymbol{F}$. graminearum nos grãos foi realizada pelo plaqueamento de 200 grãos por tratamento em meio de cultura de BDA+A (batata- 
dextrose-ágar $=$ Oxoid 39g $\mathrm{g}^{-1}+$ antibiótico $=200 \mathrm{mg} \mathrm{l}^{-1}$ de sulfato de estreptomicina).

Na safra de 2005, o experimento foi conduzido na área experimental do CAV/UDESC com a mesma cultivar. A semeadura foi realizada no dia 12 de julho, em área de plantio direto e monocultura, utilizando-se uma semeadora de parcela, mantendo uma densidade populacional próxima de 400 sementes $\mathrm{m}^{-2}$. A adubação de base constou de $250 \mathrm{~kg} \mathrm{ha}^{-1}$ da fórmula 10-20-20. O nitrogênio em cobertura foi aplicado no dia 12 de agosto na dose de $200 \mathrm{~kg} \mathrm{ha}^{-1}$ de uréia (45\% de $\mathrm{N})$. O controle de plantas daninhas foi feito na dessecação usando-se glifosato e, em pós-emergência, com metsulfuron-metil (Ally 600) para nabo e diclofopmetil (Iloxan 280 CE) para azevém. O controle de lagartas foi feito com o inseticida triflumurom e de doenças foliares com o fungicida tebuconazole.

O delineamento experimental foi de blocos casualizados com quatro repetições. As unidades experimentais constaram de cinco linhas de semeadura, espaçadas em $0,2 \mathrm{~m}$, com cinco metros de comprimento. Neste experimento, os fungicidas foram aplicados no início da antese, utilizando-se a mesma metodologia de aplicação da safra anterior. Testaram-se os seguintes fungicidas: tebuconazole (0,15L de i.a. ha $\left.{ }^{-1}\right)$, metconazole (0,09L de i.a.), piraclostrobina+epoxiconazole (Opera 133+50 SE = 0,099+0,037L de i.a.), azoxistrobina+ciproconazole (Priori Xtra 200+80 SC $=0,060+0,024 L$ de i.a.) e trifloxistrobina+tebuconazole (0,075+0,15L de i.a.),

As variáveis analisadas, intensidade da giberela, rendimento de grãos, peso de mil grãos e incidência de $\boldsymbol{F}$. graminearum nos grãos colhidos, seguiram a mesma metodologia da safra anterior

Nas duas safras, os dados obtidos foram submetidos à análise de variância e as médias comparadas pelo teste de Tukey a 5\% de probabilidade de erro, utilizando-se o programa estatístico SAS ${ }^{\circledR}$ Learning Edition 2.0 (SAS Institute Inc., 2004).

\section{RESULTADOS E DISCUSSÃO}

As menores intensidades da giberela foram detectadas com fungicidas aplicados no início e no meio da floração. Os valores do índice de giberela, na média dos quatro fungicidas, comparando épocas de aplicação, foram de 1,24, 1,76 e 2,51, respectivamente para início de floração, meio de floração e início de grão leitoso. Nesse caso, a porcentagem média no controle da giberela foi, respectivamente, de 79, 70,3 e $57,6 \%$ (Tabela 1). REIS et al. (1996a) e PANISSON et al. (2002a) relatam que o sucesso no controle da giberela ocorre quando os fungicidas atingem um maior número de anteras, o que ocorre normalmente no meio da antese completa. Porém, neste trabalho, pode-se verificar um ganho de $8,7 \%$ no controle da giberela com os fungicidas aplicados no início da floração, quando comparados com aplicação no meio do florescimento.
A menor eficiência no controle da giberela ocorreu com aplicação no início do desenvolvimento de grão leitoso, demonstrando que uma aplicação nesta fase, com os fungicidas testados, apresenta pouco efeito curativo e/ou erradicativo de $\boldsymbol{F}$. graminearum.

Os fungicidas tebuconazole, trifloxistrobina+tebuconazole e metconazole reduziram significativamente o índice de giberela quando aplicados no início e meio da antese (Tabela 1). O fungicida trifloxistrobina+tebuconazole na dose de $0,075+0,15 \mathrm{~L}$ de i.a. ha ${ }^{-1}$ foi o único que reduziu significativamente o índice de giberela quando aplicado no início do desenvolvimento de grão leitoso (Tabela 1). Em geral, os fungicidas reduziram gradualmente a porcentagem de controle da giberela com aplicação feita do início da floração até o início de desenvolvimento de grão leitoso (Tabela 1).

Os maiores rendimentos de grãos foram obtidos com aplicação no início da floração, com aumento médio relativo à testemunha de 7,01\%. Aplicações no meio da floração e no início de desenvolvimento de grão leitoso tiveram aumento médio relativo de 3,34 e 2,28\%, respectivamente (Tabela 2). O maior rendimento de grãos foi obtido com o fungicida trifloxistrobina+tebuconazole $(0,075+0,15)$ aplicado no início da floração, diferindo significativamente da testemunha, com aumento relativo de $13,7 \%$ (Tabela 2), seguido do fungicida tebuconazole $(0,15)$, com aplicação no início e no meio da floração.

Não foi detectada diferença significativa entre os tratamentos para o peso de mil grãos. No entanto, considerando-se os valores absolutos, o peso de mil grãos foi maior para todos os fungicidas nas três épocas de aplicação, quando comparado com a testemunha (Tabela 2). O fungicida trifloxistrobina+tebuconazole $(0,15+0,075)$ foi o único que reduziu significativamente a incidência de $\boldsymbol{F}$. graminearum nos grãos colhidos nas três épocas de aplicação. O fungicida metconazole apresentou maior redução na incidência do fungo com aplicação no meio da floração. Tebuconazole não reduziu significativamente a incidência de $\boldsymbol{F}$. graminearum nos grãos (Tabela 2).

Na safra 2005, todos os fungicidas reduziram significativamente a incidência, a severidade e o índice de giberela, quando comparados com a testemunha (Tabela 3). Considerando-se o índice de giberela, as porcentagens de controle variaram de 70,2\% (trifloxistrobina+tebuconazole) a 73,6\% (tebuconazole). MESTERHAZY (1996), testando fungicidas triazóis, relatou melhor controle da giberela e menor infecção dos grãos com o fungicida tebuconazole. Comparandose os dois experimentos (safras 2004 e 2005), com aplicação dos fungicidas no início da floração, verifica-se uma pequena redução na porcentagem de controle da giberela na safra 2005, fato que pode ser atribuído à maior intensidade da doença (tratamento testemunha) 
Tabela 1 - Controle da giberela do trigo na cultivar "BRS Louro” pela aplicação de fungicidas durante a floração e o início de formação do grão. Vacaria, RS, safra 2004

\begin{tabular}{|c|c|c|c|c|c|c|}
\hline Tratamentos / Dose ${ }^{1} / \mathrm{EA}^{2}$ & Incidência $^{3}$ & Controle & Severidade $^{3}$ & Controle & $\mathrm{IG}^{34}$ & Controle \\
\hline & \multicolumn{6}{|c|}{$\%$} \\
\hline Tebuconazole 0,15 / 60 EC & $16,7 b^{*}$ & 62,6 & $4,33 \mathrm{~b}$ & 67,4 & $0,72 \mathrm{~b}$ & 87,8 \\
\hline $\begin{array}{l}\text { Trifloxistrobina+Tebuconazole } \\
0,06+0,12 \text { / } 60 \text { EC }\end{array}$ & $26,3 \mathrm{ab}$ & 41,0 & $6,61 \mathrm{~b}$ & 50,3 & $1,74 \mathrm{~b}$ & 70,7 \\
\hline $\begin{array}{l}\text { Trifloxistrobina+Tebuconazole } \\
\text { 0,075+0,15 / } 60 \text { EC }\end{array}$ & $16,7 \mathrm{~b}$ & 62,6 & $4,40 \mathrm{~b}$ & 66,9 & $0,73 \mathrm{~b}$ & 87,7 \\
\hline Metconazole 0,08 / 60 EC & $26,6 \mathrm{ab}$ & 40,3 & $6,75 \mathrm{~b}$ & 49,2 & $1,79 \mathrm{~b}$ & 69,8 \\
\hline Tebuconazole 0,15 / EC 64 & $22,7 \mathrm{~b}$ & 49,1 & $5,97 \mathrm{~b}$ & 55,1 & $1,35 \mathrm{~b}$ & 77,2 \\
\hline $\begin{array}{l}\text { Trifloxistrobina+Tebuconazole } \\
0,06+0,12 \text { / EC } 64\end{array}$ & $27,7 \mathrm{ab}$ & 37,8 & $7,19 \mathrm{ab}$ & 45,9 & $1,99 b$ & 66,4 \\
\hline $\begin{array}{l}\text { Trifloxistrobina+Tebuconazole } \\
0,075+0,15 \text { / EC } 64\end{array}$ & $26,0 \mathrm{ab}$ & 41,7 & $6,99 \mathrm{~b}$ & 47,4 & $1,82 \mathrm{~b}$ & 69,3 \\
\hline Metconazole 0,08 / EC 64 & $28,0 \mathrm{ab}$ & 37,2 & $6,70 \mathrm{~b}$ & 49,6 & $1,88 \mathrm{~b}$ & 68,3 \\
\hline Tebuconazole 0,15 / EC 70 & $31,0 \mathrm{ab}$ & 30,5 & $8,89 \mathrm{ab}$ & 33,1 & $2,76 \mathrm{ab}$ & 53,5 \\
\hline $\begin{array}{l}\text { Trifloxistrobina+Tebuconazole } \\
0,06+0,12 \text { / EC } 70\end{array}$ & $30,3 \mathrm{ab}$ & 32,1 & $7,96 \mathrm{ab}$ & 40,1 & $2,41 \mathrm{ab}$ & 59,4 \\
\hline $\begin{array}{l}\text { Trifloxistrobina+Tebuconazole } \\
0,075+0,15 \text { / EC } 70\end{array}$ & $23,3 \mathrm{~b}$ & 47,7 & $6,42 \mathrm{~b}$ & 51,7 & $1,50 \mathrm{~b}$ & 74,7 \\
\hline Metconazole 0,08 / EC 70 & $36,3 \mathrm{ab}$ & 18,6 & $9,35 a b$ & 29,7 & $3,39 a b$ & 42,8 \\
\hline Testemunha & 44,6 a & -- & $13,3 \mathrm{a}$ & -- & 5,93 a & -- \\
\hline CV (\%) & 24,3 & & 28,8 & & 52,1 & \\
\hline
\end{tabular}

${ }^{1}$ Dose de ingrediente ativo $\left(\mathrm{L} \mathrm{ha}^{-1}\right.$ ); ${ }^{2}$ Época de aplicação (Estádio de Crescimento - EC 60 início de floração, EC 64 meio de floração, EC 70 início de grão leitoso); ${ }^{3}$ Avaliação feita no estádio de maturação do grão (EC 89); ${ }^{4}$ Índice de giberela; *Médias não seguidas pela mesma letra diferem significativamente pelo teste de Tukey a $5 \%$ de probabilidade de erro.

(Tabelas 1 e 3). Dos cinco fungicidas testados, metconazole, tebuconazole e trifloxistobina+ tebuconazole foram indicados para controle da giberela pela Comissão Sul-Brasileira de Pesquisa de Trigo na safra de 2005 (INDICAÇÕES, 2005). Nesta indicação técnica, os fungicidas piraclostrobina+epoxiconazole e azoxistrobina+ciproconazole constam respectivamente como sem informação e não-recomendado. Os dados de controle obtidos neste trabalho mostram que esses dois fungicidas não diferem de metconazole, tebuconazole e trifloxistobina+tebuconazole, podendo ser indicados pela Comissão de Trigo.

O maior rendimento de grãos foi obtido com o fungicida metconazole, diferindo estatisticamente da testemunha, com aumento relativo de 29,6\% (Tabela 4). Uma única aplicação de todos os fungicidas proporcionou aumento médio no rendimento de grãos em relação à testemunha de 24,3\%, variando de 15,7 até 29,6\% (Tabela 4). PANISSON et al. (2002a) relataram incremento médio no rendimento de 27,8 e $36,6 \%$, em duas épocas de semeadura, considerando a média de uma, duas e três aplicações do fungicida tebuconazole. Com uma aplicação deste fungicida, o aumento no rendimento foi de 6,99 e 21,6\%, respectivamente para cada época de semeadura (PANISSON et al., 2002a). Todos os fungicidas também aumentaram estatisticamente o peso de mil grãos, com destaque para o fungicida metconazole (Tabela 4).

Não foi detectada diferença significativa na incidência de $\boldsymbol{F}$. graminearum nos grãos colhidos (Tabela 4), confirmando o relato de PANISSON et al. (2002a) quando feita uma aplicação no início e no meio da floração. Apesar de não haver diferença significativa, os fungicidas metconazole e tebuconazole proporcionaram menor incidência do fungo nos grãos, demonstrando que estes triazóis, quando aplicados isoladamente, conferem maior proteção à infecção de F. graminearum nos grãos.

O controle médio da giberela, com base na severidade, nos dois experimentos, foi respectivamente de 58,4 e $46,6 \%$, com severidade no tratamento testemunha de 13,3 e 18,5\% (Tabelas 1 e 3 ). PANISSON et al. (2002a) relataram controle de 53,2 a 64,6\% com aplicação feita no início da floração. Os dados deste trabalho mostraram que o controle químico da giberela continua sendo tarefa difícil. Mesmo assim, quando houver uma decisão técnica favorável para o controle químico, e se for decido pela realização de uma única aplicação, esta deve ser realizada preferencialmente no início do florescimento. 
Tabela 2 - Desempenho de fungicidas e da época de aplicação no rendimento de grãos, peso de mil grãos e incidência de Fusarium graminearum em grãos de trigo cultivar “BRS Louro”. Vacaria, RS, safra 2004.

\begin{tabular}{|c|c|c|c|c|}
\hline Tratamentos / Dose ${ }^{1} / \mathrm{EA}^{2}$ & $\begin{array}{l}\text { Rendimento de } \\
\text { grãos }\end{array}$ & $\begin{array}{c}\text { Aumento em relação } \\
\text { à testemunha }\end{array}$ & $\begin{array}{l}\text { Peso de mil } \\
\text { grãos }\end{array}$ & $\begin{array}{c}\text { Incidência de Fusarium } \\
\text { graminearum }\end{array}$ \\
\hline & $\mathrm{kg} \mathrm{ha}^{-1}$ & $\%$ & g & $\%$ \\
\hline Tebuconazole 0,15 / 60 EC & $5.302 \mathrm{ab}^{*}$ & 6,38 & $37,73^{\mathrm{ns}}$ & $7,7 \mathrm{ab}$ \\
\hline $\begin{array}{l}\text { Trifloxistrobina+Tebuconazole } \\
0,06+0,12 \text { / } 60 \text { EC }\end{array}$ & $5.157 \mathrm{~b}$ & 3,47 & 37,70 & $6,0 \mathrm{~b}$ \\
\hline $\begin{array}{l}\text { Trifloxistrobina+Tebuconazole } \\
0,075+0,15 \text { / } 60 \text { EC }\end{array}$ & 5.666 a & 13,70 & 37,97 & $3,8 \mathrm{~b}$ \\
\hline Metconazole 0,08 / 60 EC & $5.208 \mathrm{~b}$ & 4,49 & 37,83 & $7,0 \mathrm{ab}$ \\
\hline Tebuconazole 0,15 / EC 64 & $5.240 \mathrm{ab}$ & 5,17 & 38,00 & $6,7 \mathrm{ab}$ \\
\hline $\begin{array}{l}\text { Trifloxistrobina+ Tebuconazole } \\
0,06+0,12 \text { / EC } 64\end{array}$ & 4996 b & 0,24 & 37,07 & $3,0 \mathrm{~b}$ \\
\hline $\begin{array}{l}\text { Trifloxistrobina+Tebuconazole } \\
0,075+0,15 \text { / EC } 64\end{array}$ & $5.208 \mathrm{~b}$ & 4,49 & 37,67 & $5,0 \mathrm{~b}$ \\
\hline Metconazole 0,08 / EC 64 & $5.157 \mathrm{~b}$ & 3,47 & 38,13 & $2,8 \mathrm{~b}$ \\
\hline Tebuconazole 0,15 / EC 70 & $5.051 \mathrm{~b}$ & 1,34 & 36,97 & $8,5 \mathrm{ab}$ \\
\hline $\begin{array}{l}\text { Trifloxistrobina+Tebuconazole } \\
0,06+0,12 \text { / EC } 70\end{array}$ & $5.145 \mathrm{~b}$ & 3,23 & 37,83 & $8,2 \mathrm{ab}$ \\
\hline $\begin{array}{l}\text { Trifloxistrobina+Tebuconazole } \\
0,075+0,15 \text { / EC } 70\end{array}$ & $5.037 \mathrm{~b}$ & 1,06 & 37,83 & $6,2 \mathrm{~b}$ \\
\hline Metconazole 0,08 / EC 70 & $5.158 \mathrm{~b}$ & 3,49 & 37,87 & $6,0 \mathrm{~b}$ \\
\hline Testemunha & $4.984 \mathrm{~b}$ & -- & 36,76 & $12,2 \mathrm{a}$ \\
\hline CV (\%) & 2,8 & & 1,6 & 35,9 \\
\hline
\end{tabular}

${ }^{1}$ Dose de ingrediente ativo $\left(\mathrm{L} \mathrm{ha}^{-1}\right)$; ${ }^{2}$ Época de aplicação (Estádio de Crescimento - EC 60 início de floração, EC 64 meio de floração, EC 70 início de grão leitoso); *Médias não seguidas pela mesma letra diferem significativamente pelo teste de Tukey a 5 \% de probabilidade de erro.

\section{CONCLUSÕES}

A eficácia de controle químico da giberela no campo e o rendimento de grãos de trigo são maiores quando as aplicações de fungicidas específicos são realizadas no início do estádio fenológico de floração.

Aplicações de fungicidas durante o florescimento e início de desenvolvimento de grão não

Tabela 3 - Controle da giberela pela aplicação de fungicidas no início da floração do trigo cultivar “BRS Louro”. Lages, SC, safra 2005.

\begin{tabular}{|c|c|c|c|c|c|c|}
\hline Tratamentos / Dose ${ }^{1}$ & Incidência $^{2}$ & Controle & Severidade $^{2}$ & Controle & $\mathrm{IG}^{3}$ & Controle \\
\hline & \multicolumn{6}{|c|}{$\%$} \\
\hline $\begin{array}{l}\text { Tebuconazole / } \\
0,15\end{array}$ & $35,6 \mathrm{~b} *$ & 48,2 & $9,45 \mathrm{~b}$ & 48,9 & $3,36 \mathrm{~b}$ & 73,6 \\
\hline $\begin{array}{l}\text { Metconazole / } \\
0,09\end{array}$ & $37,5 \mathrm{~b}$ & 45,4 & $9,75 \mathrm{~b}$ & 47,3 & $3,66 \mathrm{~b}$ & 71,2 \\
\hline $\begin{array}{l}\text { Piraclostrobina+Epoxiconazole / } \\
0,099+0,037\end{array}$ & $37,5 \mathrm{~b}$ & 45,4 & $9,95 \mathrm{~b}$ & 46,2 & $3,73 \mathrm{~b}$ & 70,6 \\
\hline $\begin{array}{l}\text { Azoxistrobina+Ciproconazole / } \\
0,060+0,024\end{array}$ & $38,7 \mathrm{~b}$ & 43,7 & $9,75 \mathrm{~b}$ & 47,3 & $3,77 \mathrm{~b}$ & 70,3 \\
\hline $\begin{array}{l}\text { Trifloxistrobina }+ \text { Tebuconazole / } \\
0,075+0,15\end{array}$ & $36,2 \mathrm{~b}$ & 47,3 & $10,45 \mathrm{~b}$ & 43,5 & $3,78 \mathrm{~b}$ & 70,2 \\
\hline Testemunha & 68,7 a & -- & $18,50 \mathrm{a}$ & -- & $12,71 \mathrm{a}$ & -- \\
\hline CV (\%) & 10,8 & & 6,4 & & 10,2 & \\
\hline
\end{tabular}

${ }^{1}$ Dose de ingrediente ativo $\left(\mathrm{L} \mathrm{ha}^{-1}\right) ;{ }^{2}$ Avaliação feita no estádio de maturação (EC 89); ${ }^{3}$ Índice de giberela; *Médias não seguidas pela mesma letra diferem significativamente pelo teste de Tukey a $5 \%$ de probabilidade de erro.

Ciência Rural, v.37, n.6,nov-dez, 2007. 
Tabela 4 - Desempenho de fungicidas aplicados no início da floração sobre o rendimento de grãos, peso de mil grãos e incidência de Fusarium graminearum em grãos de trigo cultivar "BRS Louro”. Lages, SC, safra 2005.

\begin{tabular}{|c|c|c|c|c|}
\hline Tratamentos /Dose ${ }^{1}$ & $\begin{array}{l}\text { Rendimento de } \\
\text { grãos }\end{array}$ & $\begin{array}{c}\text { Aumento em relação } \\
\text { à testemunha }\end{array}$ & $\begin{array}{l}\text { Peso de mil } \\
\text { grãos }\end{array}$ & $\begin{array}{c}\text { Incidência de Fusarium } \\
\text { graminearum }\end{array}$ \\
\hline & $\left(\mathrm{kg} \mathrm{ha}^{-1}\right)$ & $\%$ & g & $\%$ \\
\hline Tebuconazole / 0,15 & $2.322 \mathrm{ab}^{*}$ & 26,5 & $31,88 \mathrm{ab}$ & 36,5 \\
\hline Metconazole / 0,09 & 2.379 a & 29,6 & 32,68 a & 34,0 \\
\hline Piraclostrobina+Epoxiconazole / 0,099+0,037 & $2.320 \mathrm{ab}$ & 26,4 & $31,03 \mathrm{ab}$ & 51,5 \\
\hline Azoxistrobina+Ciproconazole / 0,060+0,024 & $2.261 \mathrm{ab}$ & 23,2 & $31,68 \mathrm{ab}$ & 48,0 \\
\hline Trifloxistrobina+Tebuconazole / 0,075+0,15 & $2.123 \mathrm{ab}$ & 15,7 & $31,30 \mathrm{ab}$ & 48,5 \\
\hline Testemunha & $1.835 \mathrm{~b}$ & -- & 30,48 b & 47,5 \\
\hline CV (\%) & 10,7 & & 2,55 & ns \\
\hline
\end{tabular}

${ }^{1}$ Dose de ingrediente ativo $\left(\mathrm{L} \mathrm{ha}^{-1}\right)$; *Médias não seguidas pela mesma letra diferem significativamente pelo teste de Tukey a 5 \% de probabilidade de erro.

têm reduzido significativamente a infecção de $\boldsymbol{F}$. graminearum nos grãos.

\section{REFERÊNCIAS}

CASA, R.T. et al. Danos causados pela infecção de Gibberella zeae em trigo. Fitopatologia Brasileira, Fortaleza, v.29, n.3, p.289-293, 2004a.

CASA, R.T. et al. Efeito do número de espiguetas gibereladas sobre o rendimento, o peso de mil grãos e a incidência de Fusarium graminearum em grãos de trigo. Summa Phytopathologica, Botucatu, v.30, n.2, p.277-280, 2004b.

DEL PONTE, E.M. et al. Factors affecting density of airborne Gibberella zeae inoculum. Fitopatologia Brasileira, Fortaleza, v.30, n.1, p.55-60, 2005.

INDICAÇÕES TÉCNICAS DA COMISSÃO SUL-BRASILEIRA DE PESQUISA DE TRIGO: TRIGO E TRITICALE - 2005. Comissão Sul-Brasileira de Pesquisa de Trigo, 37., 2005. Indicações. Cruz Alta, RS: FUNDACEP, 2005. 162p

LIMA, M.I.P.M. et al. Avaliação da resistência à giberela em trigo. Fitopatologia Brasileira, Fortaleza, v.25, n.1, p.3035, 2000.

McMULLEN, M. et al. Scab of wheat and barley: a re-emerging disease of devastating impact. Plant Disease, St. Paul, v.81, n.12, p.1340-1348, 1997.

MESTERHAZY, A. Fungicide control of Fusarium scab and impact on toxin contamination. In: DUBIN, H.J. et al. (Eds.). Fusarium head scab: global status and future prospects. Mexico, D.F.: CIMMYT, 1996. p.120-124.

PANISSON, E. et al. Efeito de época, do número de aplicações e de doses de fungicida no controle da giberela em trigo. Fitopatologia Brasileira, Fortaleza, v.27, n.5, p.495-499, 2002a.

PANISSON, E. et al. Quantificação de propágulos de Gibberella zeae no ar e infecção de anteras em trigo. Fitopatologia Brasileira, Fortaleza, v.27, n.5, p.484-488, 2002b.
PANISSON, E. et al. Quantificação de danos causados pela giberela em cereais de inverno, na safra 2000, em Passo Fundo, RS. Fitopatologia Brasileira, Fortaleza, v.28, n.2, p.189192, 2003.

PARRY, D.W. et al. Fusarium ear blight (scab) in small grain cereals - a review. Plant Pathology, St. Paul. v.44, n.2 p.207238, 1995.

REIS, E.M.; BLUM, M.M.C. Modelo climático para a previsão da giberela em trigo. Summa Phytopathologica, Botucatu, v.30, n.4, p.497-500, 2004.

REIS, E.M.; CASA, R.T. Sobrevivência de fitopatógenos. In: VALE, F.X.R. et al. (Eds.). Epidemiologia aplicada ao manejo de doenças de plantas. Belo Horizonte: Perffil, 2004. p.337362 .

REIS, E.M.; CASA, R.T. Doenças do trigo. In: KIMATI, H. et al. (Eds.). Manual de fitopatologia: doenças das plantas cultivadas. São Paulo: Agronômica Ceres, 2005. V.2:il. p.631638 .

REIS, E.M. et al. Controle químico de Gibberella zeae em trigo, um problema de deposição de fungicidas em anteras. Summa Phytopathologica, Jaboticabal, v.22, n.1, p.39-42, 1996a

REIS, E.M. et al. Grain losses caused by infection of wheat heads by Gibberella zeae in southern Brazil, from 1984 to 1994. Summa Phytopathologica, Jaboticabal, v.22, n.2, p.134-137, 1996b.

SAS Institute Inc. SAS ${ }^{\circledR}$. Learning Edition 2.0. Cary, NC, 2004. 86p.

SUTTON, J.C. Epidemiology of wheat head blight and maize ear rot caused by Fusarium graminearum. Canadian Journal of Plant Pathology, Vancouver, v.4, n.2, p.195-209, 1982.

ZADOKS, J.C. et al. A decimal code for the growth stages of cereals. Weed Research, Cambridge, v.14, n.4, p.415-421, 1974.

ZAMBOLIM, L. et al. Sistema plantio direto e doenças em plantas. Fitopatologia Brasileira, Fortaleza, v.25, n.4, p.585595, 2000.

Ciência Rural, v.37, n.6, nov-dez, 2007. 